\title{
Study on the Operation Mechanism of School- Enterprise Cooperation Service Platform in Personnel Training
}

\author{
Gui-Hua Li \\ Dept. of Basic Science \\ Beijing Vocational College of Agriculture \\ Beijing, China
}

\author{
Zhi-wei Li* \\ School of Mathematical Science \\ Capital Normal University \\ Beijing, China \\ *Corresponding Author
}

\begin{abstract}
Based on the current situation of education in China, the connotation and extension of knowledge platform and capability platform are designed on the basis of the research on the construction of school-enterprise cooperative personnel training service platform. The interaction and the linkage between the knowledge platform and the capability platform are analyzed. Then the Operation mode of School-Enterprise Cooperation Service Platform in Personnel Training is discussed.
\end{abstract}

Keywords-School-Enterprise Cooperation; Service Platform; Architecture Model; Operational mode

\section{INTRODUCTION}

With the rapid development of economy, lots of Chinese scholars focus on the collaborative learning and knowledge operation mechanism among enterprise, universities, governments and KIDS [1]. Freeman introduced the concept of national innovation system and discussed the important role of government policies, enterprises and their research and development work, education and training, and industrial structure [2]. Gui-hua $\mathrm{Li}$ introduced a service platform of School-enterprise cooperation in talent training and gave a structure mode of the service platform [3]. In this paper, on the basis of the researches of the service platform of Schoolenterprise cooperation in talent training, the operation mode of this service platform are studied. Furthermore, the collaborative learning and knowledge operation mechanism between schools and enterprises are discussed.

\section{SERVICE PLATFORM OF SCHOOL-ENTERPRISE COOPERATION IN TALENT TRAINING}

\section{A. Overview of Research on School-enterprise Cooperation}

School-enterprise cooperation is an effective way of vocational schools to serve the enterprise. Scholars in Vocational education deeply studied the theory of schoolenterprise cooperation.

- Case study. This kind of research on school-enterprise cooperation take pilot colleges or experimental areas as research objects. Tong [4] studies the school-enterprise

This work is supported by Humanities and Social Sciences Planning Project of China's Ministry of Education (NO.10YJAZH039 and NO. 10YJAZH045) cooperation of local vocational colleges in jiaxing city. Taking Zhejiang vocational college of mechanical and electrical technology as an example, zhou [5] explore the school-enterprise cooperation in the college. Sun [6] and Li G [7] explain their approaches of schoolenterprise cooperation in Heilongjiang vocational college of agricultural engineering and in Liuzhou vocational and technical college separately.

- Comparative study. The "dual system" training in Germany, the "sandwich" work-study system in the United Kingdom, the cooperation of education in the United States, the "TAFE" in Australia, and the industry-school cooperation in Japan were compared [8].

- Practical study. Through the concrete school-enterprise cooperation project summary, the effects of schoolenterprise cooperation are studied [9].

- Management study. Zhang [10] discusses the internship mode of students in vocational colleges from the perspective of administrative management and school-enterprise cooperation.

- Course study. Some independent curriculum development under the school-enterprise cooperation are studied from the perspective of moral education mechanism [11] and the perspective of industrial design [12] separately.

With support of information technology, G.H Li [3,13-15] introduced a virtual service platform for school-enterprise cooperation, put forward action oriented teaching method of school-enterprise cooperation, designed a service platform of School-enterprise cooperation in talent training and obtained some results on teaching knowledge flow management of the service platform.

\section{B. Service Platform architecture}

The school-enterprise cooperative talent training service platform is guided by the government to build an education complex consisting of enterprises, industry associations, science and technology parks, professional education and 
public research institutions. It can promote the effective combination of enterprise and vocational education by information technology. The service platform architecture mode can be formed as figure 1 .

Figure 1 Service platform architectural node

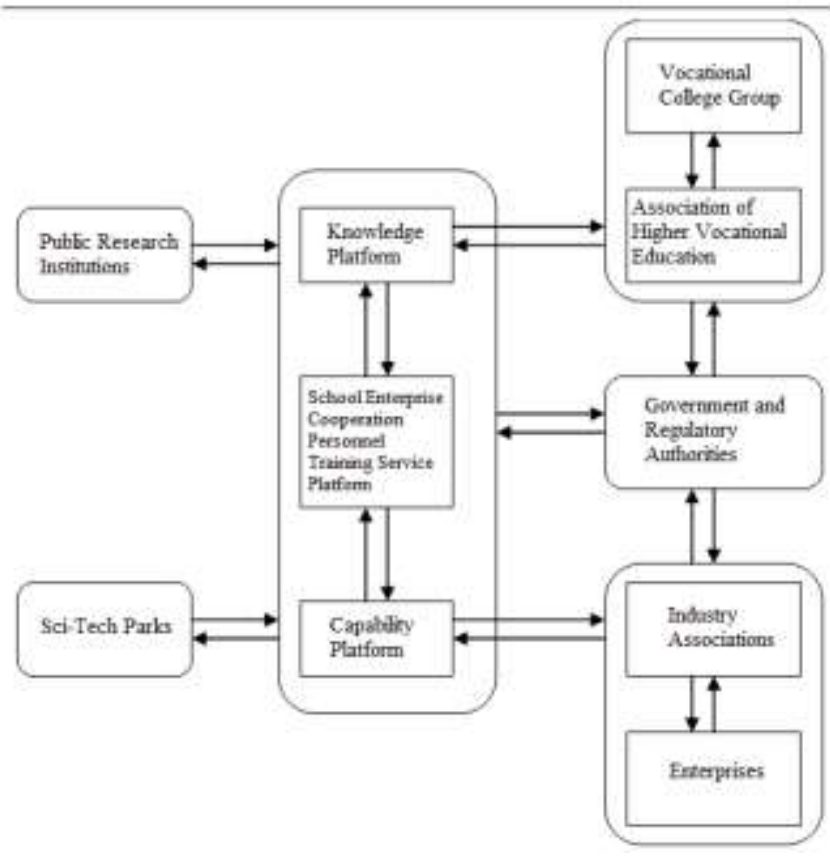

Fig. 1. Service platform architecture mode

In the service platform architecture mode of schoolenterprise cooperative talent training, government agencies formulate relevant policies to improve the efficiency of the platform system, promote the production, dissemination and diffusion of knowledge, and create a good environment for school-enterprise cooperative. Trade association and government agencies maintain close contact with each other and coordinate industrial development in accordance with national policies; Enterprises are the main body of innovation, providing new training perspectives, training bases and posts for school-enterprise cooperative. Public research institutions are mainly engaged in knowledge production activities, which are a very important source of knowledge for enterprise innovation activities and also the source of education knowledge. Science and technology parks not only innovate knowledge but also play an exemplary role in knowledge and knowledge benefits. Education and training of vocational colleges are the leading roles in the cultivation of innovative talents. They shoulder the heavy responsibility of researching new knowledge and cultivating innovative talents. Through the service platform, various factors are combined organically.

According to the definition of the service platform, the government, the enterprise and the education are the important factors of the service platform structure model. If the service platform is constructed and executed, the knowledge will be produced, diffused and used on the service platform by means of information technology. This has a positive effect on vocational education.

\section{KNOWLEDGE PLATFORM AND IT's OPERATION MECHANISM}

The knowledge platform is an important foundation for the service platform of school-enterprise cooperative talent training, which is mainly guided by higher vocational education. With the development of information technology, network technology and digital technology, there has also been great changes in education area. Teaching materials, digitization of book resources, facilitate the integration of knowledge and flow, and provide a good development environment for the establishment of knowledge platform. The operating mode of knowledge platform is illustrated as figure 2 .

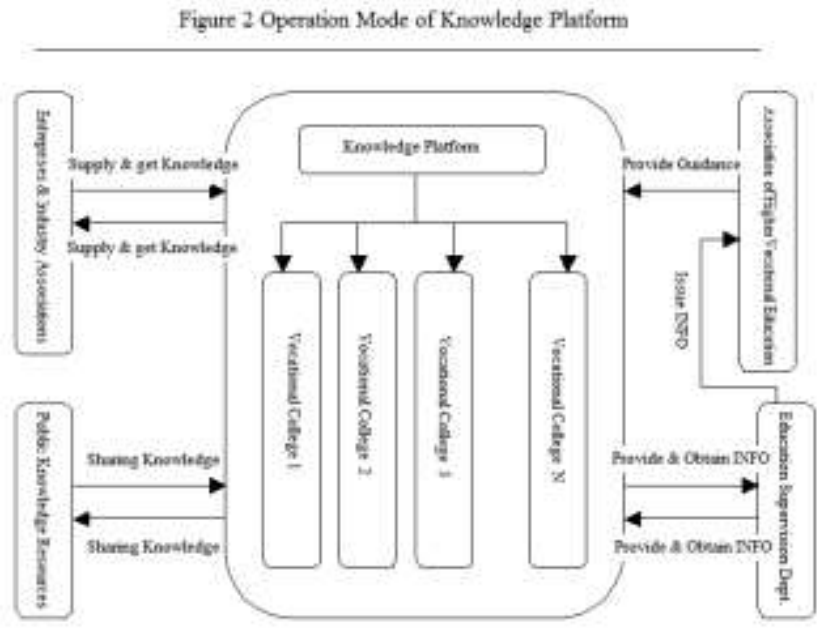

Fig. 2. Operating mode of knowledge platform

The knowledge platform is built through computer technology and network technology [14].

At first, we need to build a complete school traditional knowledge group database by integrating the knowledge network of higher vocational colleges and universities. The source of knowledge group mainly consists of as the following:

- All the topics of the courses in the various vocational colleges and universities are the basic knowledge groups. In the basic knowledge section, the innovation combination and innovative application of education and learning are the necessary components of the basic knowledge group, referred to as the explicit knowledge, which can be obtained by setting the specific problems that need to be solved. The hidden knowledge in the basic knowledge section includes the experience, technique and technology of application and creation process of application. We can implement innovation education training for students through the experimental teaching of vocational colleges, oncampus practical training, the external practice and onthe job internship, etc.. The education experience of innovation application of the explicit knowledge and the hidden knowledge in the basic knowledge section, the generalization of technology are also an important part of the basic knowledge group. The traditional knowledge database is managed according to the 
knowledge flow [15], which is convenient for the output and update of basic knowledge group.

- The education research association of various courses should understand and guide the development and research of this category. It's one part of the guiding knowledge group. The guiding knowledge group also contains the knowledge requirements of professional employment, personnel training standards and requirements of the enterprises.

- The policy and the guiding policy information of government and education regulatory departments are the macro control knowledge group part. A correct understanding of policy and guiding principles of government and education regulatory departments are conductive to the adjustment of knowledge group.

The second aspect is to attract enterprises in need of talents to participate in talent evaluation. We need to encourage employers to feedback suggestions and opinions on graduate satisfaction and training improvement, and form a comprehensive information base, which is the front-line applied knowledge group database of enterprises. It is not only convenient for the accuracy of education in training talents, but also convenient for timely meeting the needs of enterprises. At the same time, it also enriches and strengthens the basic knowledge group database.

The third aspect is to realize sharing with libraries and other public knowledge resources [15]. It may even develop into the knowledge information base of global knowledge sharing, which is the comprehensive knowledge group database. The establishment and use of the comprehensive knowledge group database will facilitate the improvement of the breadth of students' knowledge, the extension of students' professional knowledge, the comprehensive development of students' comprehensive quality and the completion of students' knowledge structure.

The fourth aspect is to pay attention to the preferential policies, daily management regulations, basic industry standards and evaluation standards and the introduction of the latest development trends for enterprises published by various government department and industry associations. We need to set up an information network in the service platform to control the information above. As the information changes at any time, we can comprehensively grasp the development trends of national innovation and adjust the focus of modern vocational education.

The government and education regulatory authorities provide information and guidance for the effectiveness of the knowledge platform in combination with the higher vocational education association. The participation of enterprises and industry associations ensures the accuracy of the knowledge platform keeping pace with the Times. The higher vocational education colleges and universities strongly guarantee the scientificity of the knowledge platform. This embodies the knowledge platform in the fundamental and dominant in school-enterprise cooperation training service platform.

\section{CAPABILITY PlATFORM AND IT'S OPERATION MECHANISM}

Capability platform is another important foundation of school-enterprise cooperative talent training service platform, which is built by enterprises. The database can be formed with information technology, network technology, digital technology and integration of enterprise culture. It is convenient for the multi-part integration and multi-direction flow of non-confidential knowledge of enterprises. Through the use of the capability platform, internal employees can realize communication and learning, enterprises can be horizontally aligned, and needs of talent capacity can be found and understand by the higher vocational colleges. The operating mode of capability platform is illustrated as figure 3 .

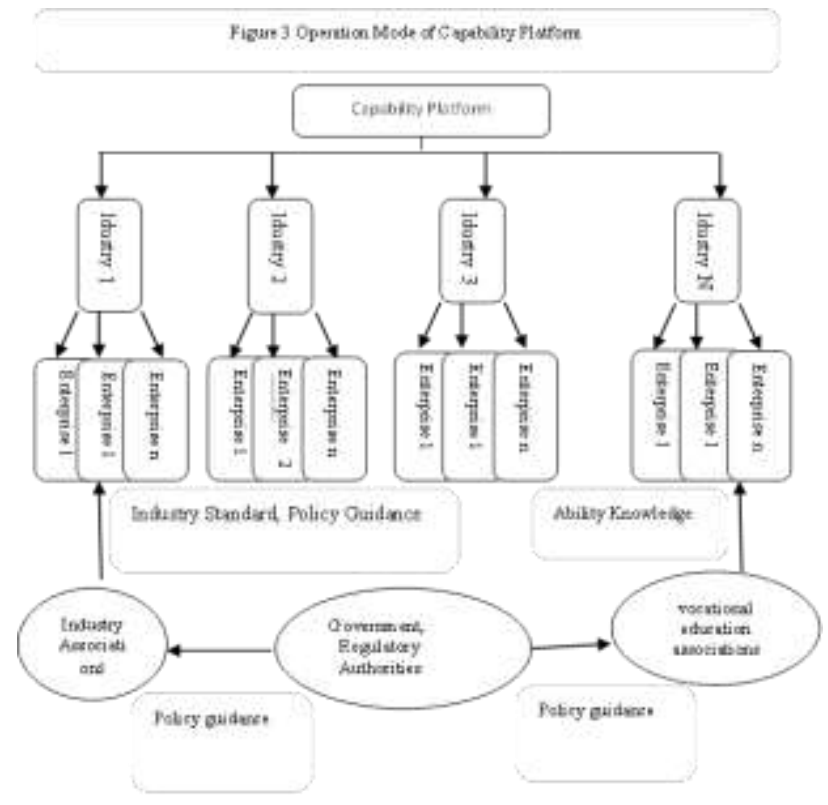

Fig. 3. Operating mode of capability platform

With the development of China's national innovation system, the cooperation network between enterprises has become an important choice for enterprises to carry out technological innovation. Interfirm cooperation, and strategic alliances between enterprises, customers, suppliers, etc are external sources of tacit knowledge [7]. There is a strong initiative for cooperation and development between enterprises and industries, which is conducive to the establishment of capability platform. The government and regulatory authorities, industry associations and vocational education associations cooperate to integrate comprehensive information of various industries and enterprises to build capacity platforms with the support of information technology and network technology.

The government and regulatory departments guide and regulate various industry associations through policies and economic interest leverage to promote the establishment of industry standards and the information of industry culture in various industries. This only promotes the self-summary and self-development of enterprises, but also promotes the learning within and between enterprises. 
All industry associations shall promote the guiding policies and industrial standards for all enterprises, realize the guidance of the industry for enterprises, fully explore the enterprise culture, analyze the demand for talents of enterprises and make clear and comprehensive display of the ability and knowledge of talents in demand. In the process, the development, diffusion, application and innovation of knowledge among enterprises in the industry continuously intact with different main elements to input, output and feedback knowledge information, which not only facilitates the exchange of knowledge and information, but also facilitates enterprises to obtain complementary resources.

The government and regulatory departments support the vocational education associations to actively and comprehensively study the talent demand and talent standard of enterprises through policies and funding. Promote the accurate formation of ability indicators and specific standards of education goals in the fields of vocational education, so as to guide the scientific and planned cultivation of diversified highinterdisciplinary talents in vocational education.

The government and regulatory departments, various industry associations and vocational education associations are combined organically through computer integrated technology. The enterprise talent demands are converted to the clear ability training indicators of vocational education. The enterprise talent ability is knowledgeable, large-scale, replicable and transferable. Finally, it's education.

\section{INTERACTION AND LINKAGE BETWEEN THE}

\section{KNOWLEDGE PLATFORM AND THE CAPABILITY PLATFORM}

The school-enterprise cooperation personnel training service platform is built with the knowledge platform and the capability platform as the core. The knowledge platform and the capability platform are not mutually independent. Two platforms are closely organized together with the involvement of government and regulatory departments, various industry associations and vocational education associations. As the platform runs, knowledge and ability innovation has gone through the process of occurrence, development and formation, training, practice and improvement, education promotion and knowledge and ability innovation. Interaction between the knowledge platform and the capability platform produces linkage effect, and finally forms a circular channel of knowledge and information flow between schools and enterprises.

In addition to the two core knowledge platform and capability platform, the operation of school-enterprise cooperation personnel training service platform also combines the group of public research institutions and the group of science and technology parks. This kind of operation mechanism guarantees the comprehensiveness and advancement of knowledge, capability and knowledge into capability, as well as guarantees the integrity of operation in school-enterprise cooperation personnel training service platform.

\section{CONCLUSION}

The service platform of School-enterprise cooperation in talent training is an education complex composed of Schools, Enterprises, Government, etc. The structure model of service platform is constructed by the knowledge platform and the capability platform. The elements and sources of knowledge platform and capability platform in the service platform are expounded, and the operation mode of the two platforms is showed respectively.

Two platforms are not independent of each other and should be closely combined by multiple factors from different aspects, so as to form a circulation channel of knowledge information flow between schools and enterprises.

\section{REFERENCES}

[1] D.Y.Xiao, Y.L. Yan, W.B.Li, Review of the Research on National Innovation System from the Perspective of Learning. Forum on Science and Technology in China, 2011(1):47-52. (In Chinese).

[2] C. Freeman, Technology Policy and Economic Performance: Lessons from Japan. London: Pinter Publishers, 1987

[3] G.H. Li, Z.W. Li, "Study on service platform architecture mode of school-enterprise cooperation in talent training", 2012 3rd International Conference on E-Business and E-Government, ICEE2012, Volume7, 5518-5521

[4] Y.F. TONG, G.L. LIU. The Research and Practice of Cooperation Mechanism Between School and Enterprise in Local Higher Vocational Colleges: To Take Jiaxing as an Example[J]. Journal of Wuxi Institute of Technology, Vol. 10 No. 1, 2011,(1):P4-7. (In Chinese)

[5] G.B. Zhou. Cooperation Models of College and Enterprise for Mutual Benefit[J]. Equipment Manufacturing Technology No.8, 2010(8): p128-129, 137. (In Chinese)

[6] B.M. Sun, Practice and Exploration of Talents Training Model of Combining Work with Learning in Higher Vocational Colleges: A Case Study of Heilongjiang Vocational College of Agricultural Engineering, Education Exploration, No. 2, 2010, Serial No.224. (In Chinese).

[7] G. Li, L.N. Zeng, Discussion and Practice of the Post Practice Mode for Higher Vocational College Students[J]. Higher Education Forum, Aug. 2011. No. 8, 2011(8): p48-50. (In Chinese).

[8] Q.H. Xing, International Comparison of the Orientation and the Role of Vocational Colleges in the Process of Cooperation between School and Enterprises[J]. Communication of Vocational Education, 2011(15): 3539. (In Chinese).

[9] Y.Q. Ma, Innovation of Teaching Management Model During Cultivation Process of High- skilled Talent with School- enterprise Cooperation[J]. Modern Manufacturing Technology and Equipment,2004(4):76-78. (In Chinese).

[10] D.M. Zhang, How Administrative Management Participate in the Cooperation between School and Enterprises[J]. Journal of Jixi University, Vol. 10 No. 3, 2010(3): p14-15. (In Chinese).

[11] F. Yao, Fen.Research on Moral Education Mechanism Based on Higher Vocational Education Mode[J]. Journal of Yellow River Conservancy Technical Institute, Vol.22 No.4, 2010(4): p75-77. (In Chinese).

[12] W.G. Han. The Research of Practical Courses on Industrial Design Base on the Cooperation of School and Enterprise[J] Art and Design, 165-167. (In Chinese).

[13] G.H. Li, Z.W. Li. Application of Information technology in Cooperation between high Vocational College and Enterprise, Compute Science. Vol 35, No. 4B,2008:371-372. (In Chinese).

[14] G.H. Li,Action - oriented Teaching Method Based on Information Technology. Compute Science. Vol.37, No. 7A,2010:13-15. (In Chinese).

[15] [15] G.H. Li, Z.W. Li. Study on Teaching Knowledge Process Management of Vocational Education[J].2011 International Conference on Computer Science and Service System, Volume 2, p1702-170. 